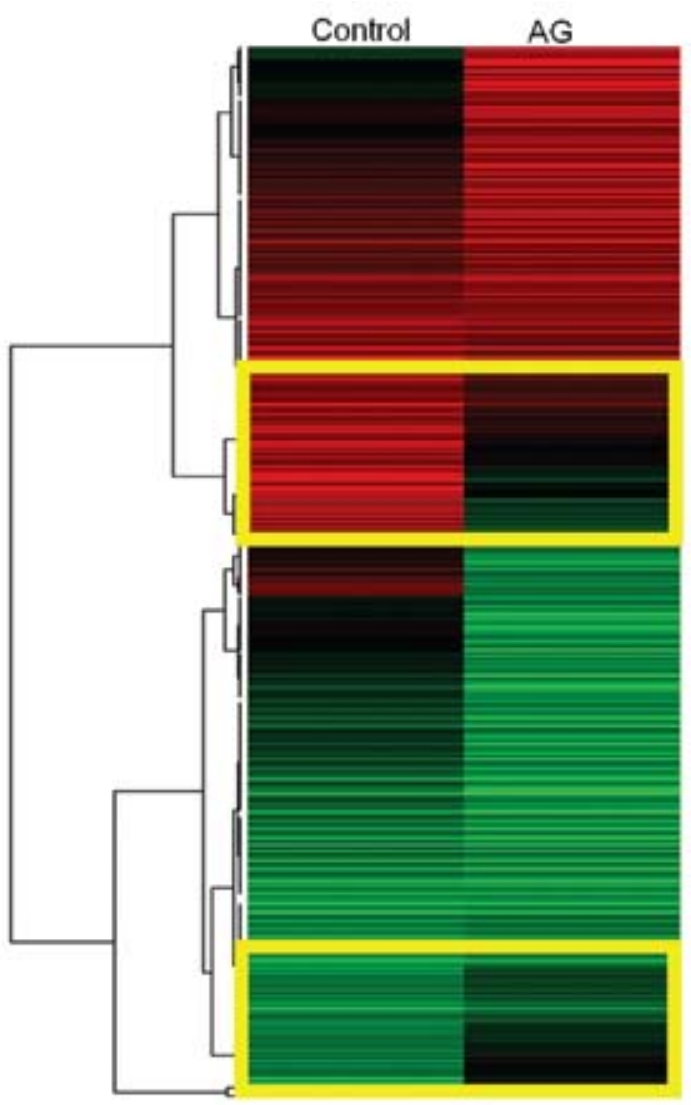

A

B

column). The network of total protein interaction was measured using Cytoscape program (right column), and some key molecules, such as IRS2, MCM10, ORC2L related in up-regulated genes, CTBP2, CD44, $\mathrm{RHOA}$, related in down-regulated genes that can be

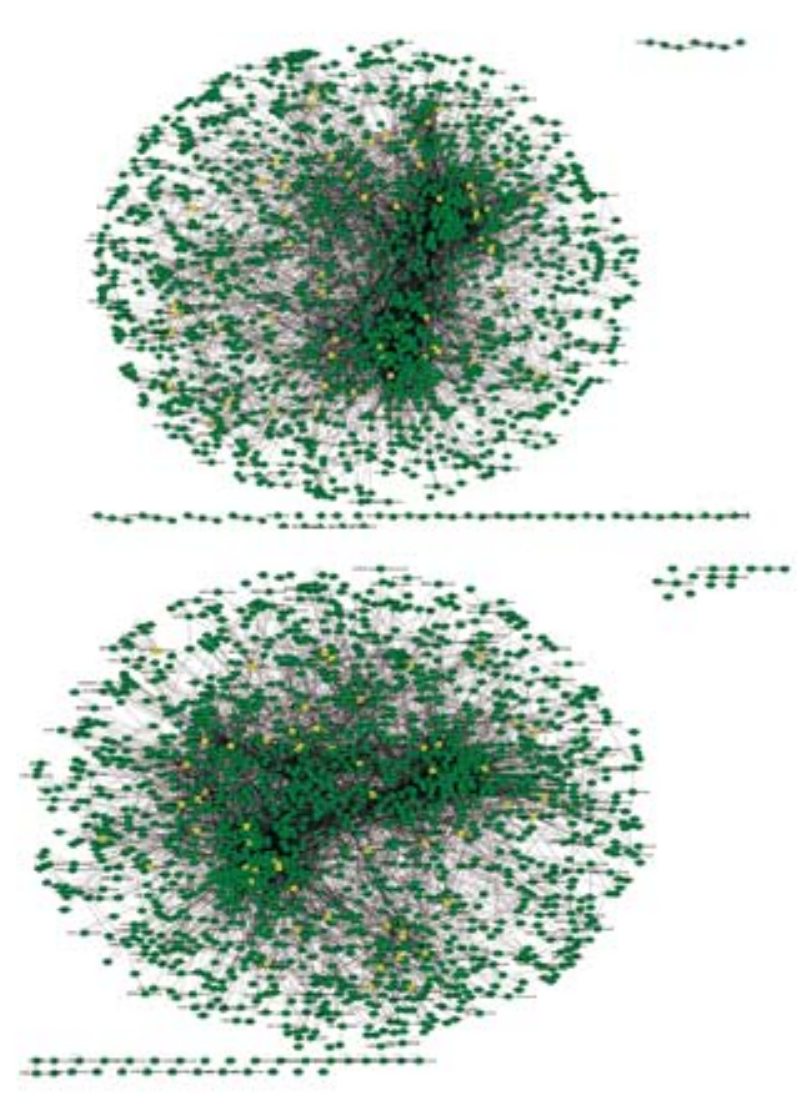

used for elucidation of therapeutic mechanism of medicine in future were identified.

References: (1) Jun K (2000) Herbology from Younglim publishing company 578-80. (2) Kang S (1977) Zhongyao Encyclopedia 102-9.

\title{
IN VITRO INHIBITORY EFFECT OF ESSENTIAL OILS AGAINST MICROBIOTA RELATED TO ORAL DISEASES
}

\section{든 Choonharuangdej S., Muadchiangka T.}

\section{Department of Oral Microbiology, Faculty of Dentistry, Mahidol University, Bangkok, Thailand}

Essential oils have been widely and effectively employed as the crucial parts of traditional Thai remedy in the field of folklore medicine for centuries. However, fewer studies have been conducted to evaluate the antimicrobial activity of these herbal extracts against some oral microorganisms closely related to oral diseases including dental caries, periodontal disease and candidiasis. Thus, some medicinal essential oils were tested for their inhibitory effects against cariogenic, periodontic and candidal pathogens. The selected essential oils were Anise (Pimpinella anisum), Cassia (Cinnamomum aromaticum), Cinnamon (Cinnamomum zeylanicum), Fennel sweet (Foeniculum vulgare), Grape fruit (Citrus maxima), Lemongrass (Cymbopogon citratus), Pine (Pinus sylvestris) and Wintergreen (Gaultheria procumbens) oils. All herbs were screened for their in- hibitory activity against cariogenic (Streptococcus mutans ATCC 25175, Lactobacillus casei) and periodontic (Porphyromonas gingivalis W50) and Candida albicans ATCC 10231 by means of agar disk diffusion. The inhibitory effect was evaluated from the appearance of inhibition zone. The results obtaining from this study can be classified into 3 major groups. For group I, cassia, cinnamon and lemongrass oils expressed inhibitory effects against all tested microorganisms with different degrees. Group II which included fennel sweet, grape fruit and wintergreen oils, in contrast, only inhibited the growth of $P$. gingivalis W50. As for group III, anise and pine oils inhibited the growth of $L$. casei and $P$. gingivalis W50. In conclusion, the selected essential oils all demonstrated antimicrobial property against one or more etiologic agents causing oral diseases. 